\title{
O objeto na anorexia - da falta do objeto ao objeto nada
}

\section{The object in anorexy - since the object's lack to the object nothing}

\section{El objeto de la anorexia - la falta del objeto y el objeto nada}

\section{Cristina Moreira Marcos*}

Pontifícia Universidade Católica de Minas Gerais - PUC-Minas, Belo Horizonte, Minas Gerais, Brasil.

\begin{abstract}
RESUMO
Para a psicanálise, o anoréxico revela que não é o objeto que conta, mas a falta do objeto. Não é o objeto alimento que é recusado ou desejado, ele vem ocupar tão somente o lugar da ausência do objeto. Esta questão está no centro do ensino de Lacan sobre a anorexia. A perspectiva fundamental destacada diz respeito à escolha anoréxica pelo nada. Buscamos, neste artigo, evidenciar de que modo a anorexia nos ensina sobre o estatuto do objeto em psicanálise. A particularidade de cada caso possibilitará a circunscrição, para cada um, do estatuto do objeto e da posição subjetiva em causa. Dois casos nos permitirão abordar, por um lado, a recusa anoréxica do objeto da falta e, por outro, a identificação ao objeto, evidenciando dois paradigmas do estatuto do objeto na anorexia. Trata-se de identificar o traço diferencial da anorexia para destacar, seja sua função de compensação ou suplência, seja sua função de defesa do desejo, que marca sua declinação neurótica.
\end{abstract}

Palavras-chave: anorexia, objeto, objeto nada, falta, psicanálise.

\section{ABSTRACT}

For psychoanalysis, the anoxeric shows that what counts is not the object, but its absence. More precisely, the object food is not refused, but it occupies the absence of object. This is the central lesson of Lacan on anorexy, the choice of nothing. In this paper, we try to articulate the status of the object in psychoanalysis, considering the particularity of different cases and their specific subjective position. We will examine two cases, that will show, on the one hand, the anorexic refusal of the object's lack, and, on the other, the identification of with the object. Our main point is the identification of the differential trait of anorexy, either the compesantion or the defense of the desire.

Keywords: anorexy, object, object nothing, lack, psychoanalysis.

\section{RESUMEN}

Para el psicoanálisis, la anoréxica revela que no es el objeto que cuenta, sino la falta de objeto. El objeto no es la comida que se rechace o se desea. Él es la ausencia del objeto. Esta pregunta está en el corazón de la 
enseñanza de Lacan sobre la anorexia. El enfoque fundamental es la elección de la anoréxica por el nada. Buscamos en este trabajo mostramos cómo la anorexia nos enseña sobre el lugar del objeto en psicoanálisis. La particularidad de cada caso, a hacer posible el establecimiento del estado del objeto y de la posición del sujeto en cuestión para cada uno. Dos casos se nos permitirá abordar, en primer lugar, la negativa del objeto de la falta y, en segundo lugar, la identificación con el objeto, que muestra dos paradigmas del lugar del objeto en la anorexia. Se trata de identificar el rasgo diferencial de la anorexia y poner de relieve su función de compensación o su función de defensa del deseo, que marca su declinación neurótica.

Palabras clave: anorexia, objeto, objeto nada, falta, psicoanálisis.

\section{I ntrodução}

De início, há que se dizer que, na perspectiva da psicanálise que adotamos, anorexia e bulimia não encerram um diagnóstico estrutural, mas são tomadas como posições subjetivas em sua pluralidade. A descrição psiquiátrica da anorexia refere-se à distorção da imagem corporal e dieta excessiva que leva à perda de peso severa com medo patológico de tornar-se gordo. O "Manual Diagnóstico e Estatístico de Transtornos Mentais DSM - V" (2014) inclui entre os transtornos alimentares, a anorexia e a bulimia nervosas. Os dois transtornos possuem aspectos comuns, como a alteração da percepção, da forma e do peso corporais, a insatisfação constante com a própria imagem, o medo de engordar, o que conduz a dietas restritivas ou práticas purgativas. Para a psicanálise, 0 anoréxico revela que não é o objeto que conta, mas a falta do objeto. Não é o objeto alimento que é recusado ou desejado, ele vem ocupar tão somente o lugar da ausência do objeto. Podemos dizer que a questão do objeto está no centro do ensino de Lacan sobre a anorexia. A perspectiva fundamental destacada diz respeito à escolha anoréxica pelo nada.

Dewambrechies La Sagna (2006) afirma que "é a clínica da anorexia mental que conduz Lacan a acrescentar o objeto nada à lista dos objetos freudianos que são o oral, o anal e o fálico (p. 376)". Não se trata do único acréscimo feito por Lacan à lista dos objetos freudianos: a voz e o olhar ocupam um lugar central entre os objetos da pulsão, sobretudo a partir do "Seminário livro 10 A angústia" (Lacan, 1962-1963/2005), evidenciando uma abordagem inédita da teoria psicanalítica da pulsão. A voz e o olhar constituem-se a partir de dois orifícios corporais que se apoiam sobre a estrutura anatomofisiológica dos órgãos auditivo e visual. Tais objetos, na relação do sujeito com o Outro, constituem-se menos como objetos ligado à demanda do Outro, como o são os objetos freudianos, do que como objetos ligados ao desejo do Outro. Embora inserido na lista dos objetos pulsionais em "Subversão do sujeito e dialética do desejo no 
inconsciente freudiano", o objeto nada surge como o mais enigmático dentre eles: “... mamilo, cíbalo, falo (objeto imaginário), fluxo urinário. (Lista impensável, senão acrescentamos conosco o fonema, o olhar, a voz, - o nada)" (Lacan, 1960/1966, p. 817).

Sendo assim, a anorexia nos ensina sobre o estatuto do objeto em psicanálise. A particularidade de cada caso possibilitará a circunscrição, para cada um, do estatuto do objeto e da posição subjetiva em causa. Dois casos nos permitirão abordar, por um lado, a recusa anoréxica do objeto da falta e, por outro, a identificação ao objeto, evidenciando dois paradigmas do estatuto do objeto na anorexia. Trata-se de identificar o traço diferencial da anorexia para destacar seja sua função de compensação ou suplência, seja sua função de defesa do desejo, que marca sua declinação neurótica.

\section{A noção de objeto em Freud e Lacan}

Em "O seminário Livro IV As relações de objeto", Lacan (19561957/1995) propõe o tema da relação de objeto na medida em que esta noção foi promovida pelos psicanalistas a um lugar central na teoria e na clínica psicanalíticas. Ao abordar a análise freudiana da fobia de Hans, Lacan promove a noção do significante e do primado do falo e reformula a noção de objeto. Ele propõe deter-se sobre a natureza do objeto - simbólico, imaginário, real - deixando para o segundo plano as modalidades de relação de objeto. Lacan se interroga se a centralidade desta noção é legítima. Desse modo, Lacan parte de uma crítica dessas posições como um desvio da teoria psicanalítica, afirmando que a noção de relação de objeto está ausente em Freud e que, nele, podemos tão somente evocar o que surge em torno da noção de objeto propriamente. Lacan assinala que Freud (1895/1987) insiste, desde "O Projeto para uma psicologia científica", no fato de que o objeto do qual se trata em psicanálise é o objeto perdido. No encontro com o objeto, trata-se sempre do objeto perdido, a ser reencontrado. Nesse seminário, vai se tratar, para Lacan, de instalar a noção da falta de objeto no centro da relação mãe-bebê, enfatizando sua função na constituição do sujeito. Temos aí a elaboração da teoria do objeto, à qual Lacan retornará quando concebe o conceito de objeto a. Em suma, a falta do objeto está no centro da discussão que Lacan desenvolve neste seminário.

Em Freud, a noção de objeto está fundada em um dos seus conceitos fundamentais, o conceito de pulsão. Entre os quatro componentes da pulsão, o objeto é o elemento mais contingente, mais variável. Ele não está originalmente vinculado à pulsão e se constitui a partir da sua aptidão em propiciar a satisfação. Sendo assim, o objeto da pulsão se diferencia do objeto biológico do instinto, este fixo e hereditariamente determinado. 
Podemos delimitar três grandes dimensões do conceito de objeto em Freud (Cf. Rabinovich, 2009). O primeiro pode ser estabelecido a partir do conceito de objeto do desejo, cujo protótipo se constrói a partir da primeira experiência de satisfação descrita no capítulo VII de "A interpretação dos sonhos" (Freud, 1900/1987) e no "O Projeto para uma psicologia científica" (Freud, 1895/1987). Em 1905, temos um novo objeto, próximo ao objeto do desejo, o objeto da pulsão parcial, constituindo a segunda dimensão. A terceira dimensão do objeto encontra-se no que Freud (1914/2004) chama de "eleição de objeto" a partir do desenvolvimento dos estudos sobre o narcisismo, trata-se do objeto de amor.

Um aspecto fundamental do objeto é que Freud o define, desde o início, como objeto perdido. É esta noção que Lacan enfatizará; o objeto enquanto perdido. Se voltarmos à descrição freudiana da primeira experiência de satisfação, temos o seguinte: a imagem mnésica de uma certa percepção permanece associada ao traço mnêmico da excitação resultante da necessidade. Quando esta necessidade surge novamente, graças a uma ligação que foi estabelecida, uma moção psíquica buscará reinvestir a imagem mnésica desta percepção e invocá-la, ou seja, reestabelecer a situação da primeira satisfação. Este impulso é chamado de desejo. A reaparição da percepção é o que chamamos de realização do desejo. Sendo assim, Freud não identifica a necessidade ao desejo. A necessidade, nascida de um estado de excitação interna, encontra sua satisfação em uma ação específica que obtém o objeto adequado, o alimento. O desejo é indissoluvelmente ligado a traços mnêmicos e encontra sua realização na reprodução alucinatória das percepções que se transformam em signos da satisfação. A busca do objeto no real é inteiramente orientada pela relação com os signos cujo agenciamento constitui o correlato do desejo que é a fantasia. Podemos concluir que o objeto se apresenta, em Freud, como inalcançável, como perdido.

Ao retomar a concepção freudiana do objeto, criticando a prevalência da noção de relação de objeto entre os pós-freudianos, Lacan (19561957/1995) problematiza a concepção desenvolvimentista dos estágios da libido e diferencia de modo rigoroso o objeto da necessidade, de ordem biológica, e o objeto do desejo, de ordem simbólica e tributário do desejo do Outro.

A anoréxica parece exibir a verdade da formulação lacaniana: "Eu te peço recusar o que te ofereço, porque não é isto." (Lacan, 1964/1988) O objeto alimento, desejado, temido e recusado, vem no lugar de uma outra coisa, designada tão somente pelo lugar vazio, pela falta do objeto. Lacan (1956-1957/1995) coloca, no centro das suas elaborações desenvolvidas em "O seminário livro 4: As relações de objeto", esta categoria da falta do objeto que determina a dialética 
"falta-demanda-desejo". A anorexia esclarece o que está em jogo nesta lógica.

Neste seminário, Lacan (1956-1957/1995) distingue as três formas da falta de objeto. A frustração situa-se sobre o plano imaginário, entretanto o objeto de que se trata aí é real. A castração só pode ser definida na categoria de uma dívida simbólica. Nela, o objeto que falta é imaginário. A privação é essencialmente uma falta real. Seu objeto é simbólico. O agente exerce também uma função na falta de objeto.

Lacan (1956-1957/1995) situa na frustração o centro das relações primitivas da criança. Tratando-se da frustração, é o Outro cuidador, frequentemente encarnado pela mãe, que desempenha um papel essencial. A frustração resulta da demanda. A presença-ausência é articulada, pelo sujeito, no registro da demanda. Esta escansão da demanda não nos dá toda a ordem simbólica, mas seu esboço. É o que oferece ao sujeito a possibilidade de aproximar a relação real de uma relação simbólica.

Lacan (1956-1957/1995) se pergunta como conceber o momento de virada no qual a relação primordial ao objeto real abre-se a uma relação mais complexa. O que se passa se o agente simbólico, a mãe, não responde mais aos apelos do sujeito? Da sua inscrição na estruturação simbólica que a constituía como objeto presenteausente em função da demanda, ela passa ao real; ela transforma-se na mãe real e o objeto real passa a objeto simbólico. $O$ agente da frustração, a mãe, torna-se real, potente. A criança depende dela para ter acesso aos objetos e esses objetos que eram objetos de satisfação transformam-se, por parte desta potência, em objetos de dom. Esses objetos não valem mais por seu valor nutritivo, mas como dom da parte do poder materno. O objeto simbólico não remete a um ente da realidade, mas ao campo do desejo do Outro. A partir daí, o objeto demandado é o que falta ao objeto da demanda, o dom de amor. Desse modo, temos delimitada a irredutibilidade entre 0 objeto do desejo e o objeto da necessidade. Podemos dizer que o quadro da anorexia histérica é a encarnação desta descontinuidade entre um e outro.

Quando a mãe alimenta, ela faz um dom de amor. A alimentação transforma-se em dom de amor, quando a mãe torna-se uma potência que pode dar ou não o objeto. A partir daí, o alimento já não é mais o objeto de satisfação da necessidade, mas prova de amor. Ele se transforma em objeto simbólico e não vale por ele mesmo, mas pelo nada que o envolve.

Chamo a atenção de vocês neste ponto para o fato de que isso vai tão longe que é possível que, para desempenhar o mesmo papel, não exista em absoluto o objeto real. Trata-se, com efeito, apenas daquilo que dá lugar a uma satisfação 
substitutiva da saturação simbólica. Apenas isso pode explicar a verdadeira função de um sintoma como o da anorexia mental. Já lhes disse que a anorexia mental não é um não comer, mas um comer nada. Eu insisto: isto quer dizer comer nada. Nada, isto é justamente algo que existe no simbólico. Não é um nicht essen, é um nichts essen (Lacan, 19561957/1995, p. 188).

Ora, não se trata do objeto real, mas do nada como objeto. Mais adiante, Lacan (1956-1957/1995) afirma menos uma negação da ação, do que uma negatividade e acrescenta que a criança saboreia a ausência enquanto tal. Por fim, Lacan conclui que a criança utiliza este nada para fazer a mãe dependente dela e faz assim uma inversão.

É aí que pode se inserir aquilo a que eu aludia há pouco, quando Ihes falei da anorexia mental. Poderíamos nos apressar um pouco e dizer que o único poder detido pelo sujeito contra a onipotência é dizer "não" no nível da ação, e introduzir aqui a dimensão do negativismo, que não deixa de ter relação com o momento que eu viso. Todavia, chamo a atenção para o fato que a experiência nos demonstra, e não sem razão, que não é no nível da ação e sob a forma do negativismo que se elabora a resistência à onipotência na relação de dependência, e sim no nível do objeto que nos apareceu sob o signo do nada. É no nível do objeto anulado como simbólico que a criança põe em cheque a sua dependência, e precisamente alimentando-se de nada. É aí que ela inverte a sua relação de dependência, fazendo-se, por esse meio, o mestre da onipotência ávida de fazê-la viver, ela que depende da onipotência. A partir daí, é ela quem depende por seu desejo, é ela quem está à sua mercê, à mercê das manifestações de seu capricho, à mercê da onipotência de si mesma (Lacan, 1956-1957/1995, p. 190).

Temos aqui o nada em seu valor dialético que permite uma inversão de forças: a criança, objeto do Outro, acaba por fazer o Outro dependente dela e o lança na angústia da impotência, como vemos acontecer com os familiares da anoréxica. A recusa do anoréxico é também um chamado, uma tentativa de abrir uma brecha no Outro onipotente. Em "A direção da cura e os princípios de seu poder", Lacan (1957-1958/1998) retoma este mesmo princípio: quando o Outro confunde os seus cuidados com o dom de amor, a criança recusa. O "não" anoréxico quer dissociar desejo e necessidade. $O$ "comer nada" revela-se, em última instância, uma defesa subjetiva do desejo. É o que o caso Nina demonstra, como veremos. 


\section{A recusa anoréxica do objeto da falta}

Em "O seminário Livro IV As relações de objeto" (Lacan, 19561957/1995), mas também em "A direção da cura e os princípios de seu poder" (Lacan, 1957-1958/1998), Lacan coloca em relevo a irredutibilidade entre o objeto do desejo - objeto simbólico - e o objeto da necessidade. O sujeito consegue recusar o próprio corpo, naquilo em que ele depende das necessidades biológicas do organismo para evidenciar a irredutibilidade do desejo à necessidade. Neste sentido, a clínica da anorexia nos ensina acerca do estatuto do objeto na psicanálise. Este é o quadro da anorexia histérica desenhado por Lacan, cujo paradigma encontramos na Bela Açougueira (Freud, 1900/1987). Em seu comentário do caso freudiano, Lacan afirma que o desejo de caviar da espirituosa histérica é um desejo de mulher satisfeita que não o quer estar. “Mas, vejam, ela não quer ser satisfeita apenas em suas verdadeiras necessidades. Quer outras, gratuitas, e, para ter toda a certeza de que o são, não quer satisfazê-las" (Lacan, 1957-1958/1998, p.631). A satisfação da necessidade aparece como engodo no qual a demanda de amor é esmagada. Conseza (2008) afirma que, dentro deste paradigma, a anorexia revela o sintoma histérico como uma mensagem endereçada ao desejo do Outro.

(...) Ao orquestrar o próprio dejeto (da comida, do sexo, do corpo feminino) como um desejo, a anoréxica coloca em cena, de modo exemplar, o estatuto simbólico metafórico do sintoma como mensagem inconsciente escrita no corpo. Essa mensagem demanda o desejo do Outro e a interpretação, mesmo que seja preciso pôr em risco a sobrevivência do corpo (Consenza, 2008, p. 35).

A anorexia coloca em evidência a recusa do objeto da necessidade e do Outro da demanda. "É a criança alimentada com mais amor que recusa o alimento e usa sua recusa como um desejo (anorexia mental)" (Lacan, 1957-1958/1998, p. 634). A satisfação da necessidade só pode aparecer como ilusão na qual a demanda de amor é eclipsada. A recusa do alimento faz surgir o que está para além da demanda, o desejo do Outro. A criança em sua recusa em satisfazer a demanda da mãe busca que a mãe deseje fora dela, pois é isto que Ihe falta para a constituição do seu desejo. Comer nada faz surgir o nada como objeto separador, como defesa subjetiva do desejo. O corpo se consome em uma tentativa de abrir uma falta no Outro. Se o Outro reduz a falta à falta de alimento, a solução do sujeito para a sustentação do seu desejo é a recusa do objeto oral. 
(...) quando o Outro, que também tem suas ideias sobre as necessidades dela (da criança), se intromete nisso e, no lugar daquilo que não tem, empanturra-a com a papinha sufocante daquilo que ele tem, ou seja, confunde seus cuidados com o dom de seu amor. (...) Afinal de contas, a criança, ao se recusar a satisfazer a demanda da mãe, não exige que a mãe tenha um desejo fora dela porquanto é essa a via que lhe falta rumo ao desejo? (Lacan, 1957-1958/1998, p. 634).

Nina é uma adolescente de 16 anos que chega ao "NIAB - Núcleo de Investigação da Anorexia e Bulimia do Hospital das Clínicas da UFMG 1" - com o diagnóstico de anorexia feito pelo clínico. Ela afirma que seu problema é a falta do pai. Sua relação com o pai é descrita como conflituosa: encarregado de pagar a pensão alimentícia, suas compras são sempre insuficientes. A convivência com o pai é definida como pouco nutritiva. Quanto à mãe, Nina dirá:

Ela me dá tudo, mas eu não quero tudo, eu não quero os presentes que ela me dá pelas manhãs, eu não quero que ela me dê dinheiro, EU SÓ QUERO AMOR. Acho que ela me dá o amor de um jeito diferente, um jeito que me faz mal... e como não sei dizer isso à ela... Complica um pouco né? (Cunha e Lima, 2012, p. 9)

A insuficiência do pai parece deixar Nina à mercê do desejo da mãe, entregue a um amor que faz mal. Lacan (1957-1958/1998) nos ensina em "A direção da cura" que a criança pode recusar o alimento para defender a dimensão do desejo. Quando a mãe confunde seus cuidados com o dom de amor, a criança recusa o alimento e afirma sua recusa como um desejo, exigindo que a mãe deseje fora dela. Assim, Lacan une desejo e amor. Lacan (1957-1958/1998) se refere à anorexia como ligada à ameaça da perda de amor que não se confunde com os cuidados maternos. "Desde sua primeira mamada já se pode começar a criar este hiato que fará com que será na recusa de se alimentar que ele encontrará o testemunho exigido por ele do amor de seu parceiro materno" (Lacan, (1957-1958/1998, p. 499).

Lacan (1956-1957/1995) não deixa de incluir o gozo no comer nada da criança. Ele afirma que a verdadeira função de um sintoma como o da anorexia - que não é um não comer, mas um "comer nada" - é ser uma satisfação substitutiva.

Este ponto é indispensável para compreender a fenomenologia da anorexia mental. O que está em questão neste detalhe é que a criança come nada, o que é diferente da negação da atividade. Esta ausência saboreada com tal, ela a emprega diante daquilo que tem à sua frente, a saber, a mãe de quem 
depende. Graças a este nada, ela faz a mãe depender dela (Lacan, 1956-1957/1995, p. 188).

Lacan (1956-1957/1995) se refere, nestes casos, explicitamente à anorexia infantil. Penso que podemos dizer que há, em Nina, uma conduta anoréxica infantil, na qual se desenvolve a relação com o Outro materno e a dialética da demanda e do desejo. Nesta operação, Nina converte-se em mestre, invertendo a relação de dependência.

\section{0 anoréxico e a identificação ao objeto}

A partir de "O Seminário, livro 10: a angústia" (Lacan, 1962$1963 / 2005$ ) e "O seminário, livro 11: os quatro conceitos fundamentais da psicanálise" (Lacan, 1964/1988), podemos dizer que a abordagem da anorexia passa a ser fundada no objeto a e no gozo. Daí se infere que o paradigma histérico da anorexia não é universalizável. Lacan destaca aí um objeto particular, o objeto nada. $\mathrm{Na}$ passagem do "desejo de nada" ao "objeto nada", redefine-se o estatuto do objeto na anorexia. O nada adquire um estatuto afirmativo de objeto substância de gozo. O nada, ao contrário do objeto que alimenta o desejo, revela-se um objeto parasita que anula o desejo sob a forma de um gozo totalitário.

De fato, o nada adquire o estatuto afirmativo de objeto substância de gozo que habita o corpo da anoréxica, pára em sua boca e no conjunto das zonas erógenas, produzindo nela um duplo movimento: fechamento em relação ao Outro e satisfação independente, nirvânica e autodestrutiva, quase toxicomaníaca (Consenza, 2008, p. 36).

Recalcati (2003) propõe pensar uma clínica diferencial da anorexia a partir dos dois nadas. O primeiro comer nada estaria ligado à histeria, na qual a recusa do alimento funciona como defesa do desejo, resposta à demanda sufocante do Outro. Visa-se fazer surgir o signo do amor no Outro. É o paradigma da anorexia histérica, desenvolvido principalmente em "O seminário Livro IV As relações de objeto" (Lacan, 1956-1957/1995), mas também em “A direção da cura e os princípios de seu poder" (Lacan, 1957-1958/1998). O segundo nada está ligado a formas mais graves de anorexia, nas quais se verifica uma estrutura psicótica e uma nirvanização do desejo. Há um nada que não entra na dialética do desejo e da demanda. Temos aqui a anorexia como toxicomania do nada, vertente na qual o gozo mortífero ganha o primeiro plano da cena. 
A proposta de Recalcati de situar a clínica da anorexia a partir de duas concepções distintas do objeto nada funda-se nos desdobramentos que a noção de objeto a vai encontrar no ensino de Lacan. Um breve percurso acerca desta noção nos auxilia a compreender os contornos que o objeto a vai ganhando e de que modo seu estatuto está no centro da clínica da anorexia. Lacan (1956-1957/1995) retoma a teoria do objeto desenvolvida no Seminário 4 quando concebe o objeto a, considerado por ele como sua única invenção. O objeto a nomeia a falta, constituída a partir de uma perda que não é reparável, na medida em que ela é condição para a constituição subjetiva. Para nomear algo que não pode ser representado, Lacan coloca uma letra, o "a", no lugar da falta, fazendo desta letra a própria falta. Embora não seja nossa intenção percorrer exaustivamente o desenvolvimento do objeto a no ensino de Lacan, há que se estabelecer algumas balizas teóricas deste conceito. A letra a designa, antes de tudo, o outro especular, o semelhante, primeiro objeto do desejo e de identificação essencial no estádio do espelho, a partir do qual a criança constitui seu eu e seus objetos. Em "O seminário IV A relação de objeto" (Lacan, 19561957/1995), Lacan assinala que o desejo, para além de sua dimensão imaginária, se endereça essencialmente à falta e que a falta está no centro de toda relação com o objeto. Até "As formações do inconsciente" (Lacan, 1957-1958/1998) a designa o outro, os objetos do eu e o eu. O esquema $L$ apresenta duas versões nas quais a e a' permutam-se preservando suas coerências: a relação imaginária eu-outro e seus objetos fazem obstáculo à mensagem simbólica entre A e S.

É somente a partir de "O desejo e sua interpretação" (Lacan, 19581959/2013) que o objeto a será considerado como uma categoria especial de objeto: não especularizável, chamada de "objeto de desejo" e posteriormente de "objeto causa de desejo". Nesse momento, o objeto apresenta uma dimensão de engodo à qual Lacan opõe o caráter real do objeto a. É ainda neste seminário que Lacan apresenta a fórmula da fantasia, assinalando que ela não é inteiramente solúvel na relação imaginária. A fórmula da fantasia evidencia uma relação heterogênea, na qual o sujeito, da ordem do significante, é colocado em relação com o objeto, da ordem do real. Os elementos não são mais homogêneos como no eixo imaginário a a'. Ao contrário, toda a complexidade da relação sujeito/objeto é fundada no fato de que eles são elementos heterogêneos. A questão que se impõe é a de saber como integrar o que está fora do significante no significante, dito de outro modo, como articular o objeto a, heterogêneo ao significante, com a lógica significante. Esta questão está no centro da experiência analítica: em que uma experiência baseada na palavra pode modificar a relação do sujeito com o gozo? Como podemos atingir o que não é da ordem do 
significante pelo significante? - esta é a questão colocada pelo objeto a.

Em “O seminário livro 8 A transferência” (Lacan, 1960-1961/2001), o objeto a é o agalma no amor de transferência. Em "O seminário livro 9 A identificação" (Lacan, 1961-1962/2014), a topologia do objeto a toma forma levando a pensá-lo como não especularizável, não representável. Lacan extrai as consequências desses desenvolvimentos topológicos e articula o objeto a à clínica, em "O seminário livro 10 A angústia" (Lacan, 1962-1963/2005). A experiência da angústia fornece a Lacan os elementos necessários para a construção do conceito de objeto a, assim como as razões teóricas e clínicas. Sendo assim, a angústia é considerada a única tradução subjetiva do objeto a. A angústia está ligada ao enigma do desejo do Outro, eu não sei qual objeto a eu sou no desejo do Outro. Lacan (1962-1963/2005) faz uma equivalência entre a libra de carne e o objeto a enquanto ele é separado. O objeto a é um pedaço de corpo, um pedaço de carne, uma parte de nós tomada na máquina formal (do significante) e que não é recuperável. Esta parte corporal é o objeto perdido suporte da função de causa. Este novo estatuto do objeto determina um corpo diferente do corpo do estádio do espelho ou do corpo significantizado que encontramos no Seminário 4. Não se trata mais do corpo visual do estádio do espelho, mas do corpo libidinal, o corpo das zonas erógenas. O corpo da boa forma dá lugar ao corpo disforme. No seminário 10, objeto a é particularmente corporal. Para abordá-lo, Lacan (1962-1963/2005) parte de descrições realistas e anatômicas do corpo. Isto nos dá uma descrição inédita dos objetos parciais, diferente do que encontramos no seminário das relações de objeto. Temos uma topologia estranha do corpo para a qual o esquema de duas dimensões não é suficiente, que não é mais estruturado pelo dentro e fora ou pelo face a face do espelho porque aquilo que é o mais íntimo de mim está no exterior, não porque ele foi projetado, mas porque ele foi de mim cortado. Consenza (2011) afirma que Jacques Alain-Miller traz uma importante contribuição no esclarecimento do estatuto do objeto nada em Lacan: Primeiro ponto, o objeto nada é um objeto entre os objetos pulsionais mas, ao mesmo tempo, adquire um estatuto especial. Diferentemente do seio, das fezes, do falo, da voz, do olhar, o nada não pode ter uma localização libidinal precisa nas zonas erógenas corporais. O objeto nada é o único objeto não localizável de modo específico e exclusivo sobre uma única zona erógena. Não devemos enviá-lo necessariamente ao objeto oral. Ele não tem uma localização pré-definida e só pode ser identificado a partir do caso. Segundo ponto, o objeto nada é o único objeto a que não funciona como causa do desejo. Ele encarna uma função de anti-desejo. Sua ação como objeto causa é uma ação de inércia, desvitalizante. O objeto a como 
nada seria o único entre os objetos a que é causa de não desejo, dito de outro modo, é causa de deserto, desertifica.

Se o objeto nada é dificilmente integrado a uma zona erógena precisa, ele gravita o corpo pulsional e parasita as zonas erógenas. Consenza (2011) afirma que foi Augustin Ménard o primeiro analista de orientação lacaniana a identificar um duplo estatuto do objeto nada, no final dos anos 80 . De um lado, o nada é ligado à dialética do Outro enquanto "objet-en-fonction-de-désir" e, deste modo, ponto central da divisão do sujeito, ligado à castração simbólica e coordenado pela função fálica. Temos aqui o objeto nada que encontramos na clínica da histeria, do qual falamos acima e cujo paradigma encontra-se desenhado no caso freudiano da Bela Açougueira. Neste caso, o nada é a falta de objeto cuja função é preservar o desejo pela manutenção da sua insatisfação. Esta função do nada é ilustrada pela anorexia histérica e pela falicização do corpo magro da qual fala Lacan em "A direção da cura e os princípios de seu poder" (Lacan, 1957-1958/1998).

De outro lado, o nada também aparece na clínica da anorexia como "objet-en-fonction-de-jouissance". Aqui, o gozo não é contido pela função fálica e se apresenta sem limite, fora do discurso. Estamos, neste terreno, fora das coordenadas fálicas e edipianas próprias a neurose. A ação anoréxica, destacada por Lacan, - "Eu como nada" vai na contramão de uma manobra visando a abertura de uma falta no Outro que pudesse revelar o lugar do sujeito no desejo do Outro. Ao contrário, a ação - comer nada - é um movimento de fechamento do espaço da falta, uma recusa do saber inconsciente.

Um depoimento autobiográfico publicado em "Todo o pão do mundoCrônica de uma vida entre a anorexia e a bulimia" (De Clercq, 2012) demonstra aquilo que da anorexia excede o paradigma histérico, revelando o "agir como toxicomania do nada" do sujeito anoréxico no qual ele se deixa levar rumo à morte, revelando uma vertente pela qual o sujeito anoréxico encarna o objeto a. Em Fabíola de Clercq, vemos um vínculo de sujeição ao alimento, do qual ela se torna escrava. Mas de que objeto se trata? Essa sujeição ganha forma aos 13 anos, durante a adolescência, momento em que se vê confrontada com a transformação do corpo, própria à idade, mas que será tomada como inaceitável, uma sensação de inchaço que provoca angústia. Iniciam-se as dietas, os remédios, os jejuns implacáveis e, por fim, o vômito. A estética perdida com o aumento de peso era o assunto privilegiado das discussões com a mãe, transformada em um ideal de beleza feminina inatingível.

No testemunho de Fabíola, há uma recusa da palavra que surge sob a forma de "ser um objeto", ou ainda, "realizar-se em um objeto". O objeto nada é o objeto que parasita o corpo anoréxico, reduzindo o sujeito a um objeto pleno de gozo, no qual a palavra perde sua função. Lacan (1967-1968/2014a) articula a passagem ao ato a um 
"sou e não penso". Nela, há um rechaço do inconsciente. As crises, em Fabíola, parecem implicar um "não penso, somente sou esta marca". Fabíola afirma: "Minha pele está amarelada e uma penugem loura e espessa me recobre o rosto e o resto do corpo. São esses os sinais da anorexia que conheço e que me confortam". (De Clerck, 2012 , p. 56) Não haveria aqui uma identificação ao objeto?

Presa entre o olhar obsceno do abusador e dos homens e o não-olhar da mãe, Fabíola dirá que não obteve licença para viver. (De Clerck, 2012 p. 74) Esta falha na constituição, afeta diretamente uma prática de gozo que parece excluir a existência do inconsciente. Este gozo não se insere no intercâmbio com o outro; trata-se de um gozo assexuado, vinculado a uma prática pulsional determinada que exclui o Outro. Esse gozo não passa pela parceria sexual, eliminando o parceiro e revelando a desconexão entre o sujeito e o Outro. Nas crises de vômito, evidencia-se um circuito fechado da pulsão que suprime o encontro com o outro.

Esta ruptura do sujeito com o Outro tem como efeito uma contenção do objeto, de modo narcísico, no corpo do sujeito. O objeto não se encontra perdido, ao contrário, ele é mantido ao alcance da boca.

Engulo tudo rapidamente, já não sinto mais os sabores, entrevejo com dificuldade o que, furtivamente, estou engolindo. Com uma das mãos levo comida à boca, com a outra, busco ainda mais, assim às cegas. E cozinho também, mas o que conta agora é a quantidade, devo armazenar quanta comida meu estômago dê conta de conter (De Clerck, 2012, p.59).

O objeto a não está no campo do Outro, mas permanece preso ao sujeito a tal ponto que o sujeito coincide com o objeto. Em Fabíola, essa identificação do sujeito com o objeto ganha a forma de um fechamento, de uma desvitalização, de um empobrecimento da palavra, de uma obssessão pela comida e pelo próprio peso, da ausência de uma subjetivação do sentido. "Sou um recipiente provisório". (De Clerck, 2012, p. 60) ou "(...) sou agora um esqueleto". (De Clerck, 2012, p. 65), escreve Fabíola situando-se em uma posição de objeto.

Em "O seminário, livro 11: Os quatro conceitos fundamentais da psicanálise", Lacan (1964/1988) afirma que a anorexia nos ensina como o sujeito oferece ao desejo do Outro a fantasia do seu próprio desaparecimento.

O desejo do Outro é apreendido pelo sujeito naquilo que não cola, nas faltas do discurso do Outro, e todos os por quês? da criança testemunham menos de uma avidez da razão das coisas do que constituem uma colocação em prova do adulto, 
um por que será que você me diz isso? sempre re-suscitado de seu fundo, que é o enigma do desejo do adulto. Ora, para responder a essa pega, tal como o Gribouille, sujeito traz resposta a da falta antecedente de seu próprio desaparecimento, que ele vem aqui situar no ponto da falta percebida no Outro. O primeiro objeto que ele propõe a esse desejo parental cujo objeto é desconhecido, é sua própria perda - Pode ele me perder? A fantasia de sua morte, de seu desaparecimento, é o primeiro objeto que o sujeito tem a pôr em jogo nessa dialética, e ele o põe, com efeito - sabemos disto por mil fatos, ainda que fosse pela anorexia mental (Lacan, 1964/1988, p. 203).

As perguntas das crianças apontam para um ponto de falta no discurso que configura a existência de um desejo no adulto. Ele me diz para comer, mas o que ele quer? Para além de sua demanda, o que ele deseja? Nos intervalos dos significantes, surge o desejo do Outro enquanto enigmático. O sujeito não sabe o que oferecer e fará como Gribouille que responde com o que tem à mão. Ao encontrar um cortejo fúnebre, Gribouille saúda a todos alegremente desejandoIhes um bom dia. Repreendido pelos outros, que lhe advertem que ele deveria prestar seus pêsames, continua seu caminho e encontra um cortejo nupcial ao qual ele anuncia seu pesar. Novamente, é repreendido. Lacan afirma que o sujeito traz a resposta da falta antecedente de seu próprio desaparecimento, que ele situa no ponto da falta percebida no Outro. O sujeito responde com a fantasia do seu próprio desaparecimento à pergunta: "ele me diz isso, mas o que ele quer?" (Lacan, 1964/1988, p. 203). A afânise, até o momento colocada como efeito da alienação significante, deve passar a ser função (Lacan, 1964/1988, p. 205) que permite interrogar o desejo do Outro. Esta função sustentada pela pergunta "Pode ele me perder", não fracassaria na anorexia? A anoréxica parece não poder deixar de colocar em jogo a função afânise à espera de uma resposta afirmativa que não chega.

Eidelberg (2009) nos lembra que o real que escapa à mortificação simbólica do significante sobre o corpo constitui-se como resto que, nos seminários 10 e 11, é nomeado como objeto a. Este resto do real chamado de objeto a está articulado ao menos phi, à castração. Ele pode retornar no imaginário e perturbá-lo, como ocorre em alguns casos de anorexia. Se podemos dizer que a imagem vela o menos phi, ela também esconde, recobre, o objeto. Na verdade, o objeto deve permanecer invisível no campo imaginário. Se a castração é revelada, a imagem narcísica pode ser perturbada. O imaginário é, em certo sentido, um envoltório do gozo e pode ocorrer que o objeto a, enquanto gozo, rompa com seu invólucro imaginário e surja um excesso na imagem do corpo. O autor afirma que este excesso 
evidencia-se no espelho para a anoréxica quando ela se vê gorda apesar do jejum. Quando o objeto a retorna como excesso na imagem, o jejum é um recurso para controlar este excesso. Na anorexia, afirma Eidelberg (2009), o menos também pode se converter em excesso através de uma insistência do menos, cada vez menos, para defender-se do excesso do objeto que deveria ter permanecido velado. Assim, o menos phi surge encarnado no corpo. É um menos phi que é um menos, mas paradoxalmente funciona como um mais.

Para Fabíola, diferentemente da criança, não é simbolicamente que se coloca em cena a fantasia de desaparecimento, ela a encarna no real de seu corpo. Eidelberg (2009) fala do que excede a histeria na anorexia quando não se trata do menos phj convertendo o objeto oral em nada, mas sim quando o menos phi afeta a imagem do corpo mesmo. É o corpo próprio que se converte em nada.

Parece-nos que, em Fabíola, o nada não é mais a falta do objeto, é o objeto nada. Neste sentido, é importante fazer a diferença entre o semblante de objeto a ao qual se identifica a histérica e a identificação real com a perda que se pode observar na posição melancólica. (Ménard, 2000) Podemos distinguir, por um lado, o ser "nada" como fantasia de desaparecimento, em Nina, constituindo um acting anoréxico com o qual o sujeito ameaça o Outro com sua perda e, por outro, o suicídio lento através do qual realiza-se, em Fabíola, a passagem ao deixar de comer, identificada ao dejeto (Eidelberg, 2009).

Fabíola e Nina nos ensinam acerca do estatuto do objeto para a psicanálise. Nina evidencia o paradigma histérico da anorexia no qual se destaca a irredutibilidade entre o objeto do desejo - objeto simbólico - e o objeto da necessidade. A satisfação da necessidade só pode aparecer como ilusão na qual a demanda de amor é eclipsada. A recusa anoréxica, "desejo de nada", faz surgir o que está para além da demanda, o desejo do Outro. Comer nada traz à tona o nada como objeto separador, como defesa subjetiva do desejo. Em Fabíola, o nada adquire um estatuto afirmativo de substância de gozo. Ao contrário do objeto que alimenta o desejo, o nada aqui funciona como parasita que anula o desejo sob um gozo totalitário. Uma e outra ensinam sobre as diferentes declinações do objeto nada. Podemos identificar, de um lado, o objeto em sua função de defesa do desejo marcando a declinação neurótica da anorexia e, de outro, em sua função de suplência preso ao sujeito a tal ponto que ele se identifica ao objeto.

\section{Referências}


Consenza, D. (2008). "Anorexia". In: AMP. Scilicet. Os objetos na experiência psicanalítica. Rio de Janeiro: Contracapa.

Consenza, D. (2011). Le refus dans l'anorexie. Tese de doutoramento não publicada. Université de Paris 8, France.

Cunha, C. de F. \& Lima, N. L. (2012). Uma delicada transição: adolescência, anorexia e escrita. Revista Latinoamericana de Psicopatologia Fundamental, 15(4), 798-811. Recuperado em 19 de abril de 2014, de http: //www.scielo.br/scielo.php?script=sci_arttext\&pid=S141547142012000400004\&lng=pt\&tlng=pt. 10.1590/S141547142012000400004.

De Clercq, F. (2012). Todo pão do mundo. Crônica de uma vida entre a anorexia e a bulimia. Belo Horizonte: Scriptum.

Dewambrechies La Sagna, C. (2006). L'anorexie vraie de la jeune fille. La Cause Freudienne, 63, 57-70.

DSM-V. (2014). Manual diagnóstico e estatístico de transtornos mentais [American Psychiatric Association]. Porto Alegre: Artmed

Eidelberg, A. (2009). Excesos y declinaciones del objeto nada. In: A. Eidelberg, C. Godoy \& N. S. Dafunchio (Eds.), Porciones de nada. La anorexia y la época (pp. 105-119). Buenos Aires: Del Bucle.

Freud, S. (1987). O projeto para uma psicologia científica. In Edição standard brasileira das obras psicológicas completas de Sigmund Freud (J. Salomão, trad., Vol. 1, pp. 301-409). Rio de Janeiro: I mago. (Obra originalmente publicada em 1895).

Freud, S. (1987). A interpretação dos sonhos. In Edição standard brasileira das obras psicológicas completas de Sigmund Freud (J. Salomão, trad., Vol. 5, pp. 468-566). Rio de Janeiro: Imago. (Obra originalmente publicada em 1900).

Freud, S. (1987). Os três ensaios sobre a sexualidade. In Edição standard brasileira das obras psicológicas completas de Sigmund Freud (J. Salomão, trad., Vol. 7, pp. 123-250). Rio de Janeiro: I mago. (Obra originalmente publicada em 1905).

Freud, S. (2004). À guisa de introdução ao narcisismo. Escritos sobre a psicologia do inconsciente (pp. 95-131). Rio de Janeiro: I mago. (Obra originalmente publicada em 1914).

Lacan, J. (1966). La direction de la cure et les principes de son pouvoir. In J. Lacan Ecrits. (pp.585-645). Paris: Seuil. (Obra originalmente publicada em 1958).

Lacan, J. (1966a). Subversion du sujet et dialectique du désir. In J. Lacan Ecrits. (pp.793-827). Paris: Seuil. (Obra originalmente publicada em 1960).

Lacan, J. (1973). Le séminaire livre XI Les quatres concepts fondamentaux de la psychanalyse. Paris: Seuil. (Obra originalmente publicada em 1964). 
Lacan, J. (1988). O seminário livro 11 os quatro conceitos fundamentais da psicanálise. Rio de Janeiro: Zahar. (Obra originalmente publicada em 1964).

Lacan, J. (1995). O seminário livro 4 a relação de objeto. Rio de J aneiro: Zahar. (Obra originalmente publicada em 1956-1957).

Lacan, J. (1998). Le séminaire livre $V$ Les formations de l'inconscient. Paris: Seuil, (Obra originalmente publicada em 1957-1958).

Lacan, J. (2001). Le séminaire livre VIII Le transfer. Paris: Seuil. (Obra originalmente publicada em 1960-1961).

Lacan, J. (2005). O seminário livro 10 a angústia. Rio de Janeiro: Zahar. (Obra originalmente publicada em 1962-1963).

Lacan, J. (2013). Le séminaire livre VI Le désir et son interprétation. Paris: Seuil. (Obra originalmente publicada em 1958-1959).

Lacan, J. (2014). Le séminaire livre IX L'identification. Recuperado em 10 de julho de 2014 de http://gaogoa.free.fr/SeminaireS.htm Manuscrit. (Obra originalmente publicada em 1961-1962).

Lacan, J. (2014a). Le séminaire livre XV L'acte analytique. Recuperado em 10 de julho de 2014 de http://gaogoa.free.fr/SeminaireS.htm Manuscrit. (Obra originalmente publicada em 1967-1968).

Ménard, A. (2000). O objeto na anorexia. Agente Revista de Psicanálise da EBP-Bahia, 13, 97-107.

Rabinovitch, D. S. (2009). O conceito de objeto em Freud. Rio de Janeiro: Cia de Freud.

Recalcati, M. (2003). Las dos 'nada' de la anorexia, In M. Recalcati. Clínica del vacío: Anorexia, dependencias, psicosis. (pp. 19-31). Madrid: Editorial Síntesis.

\section{Endereço para correspondência \\ Cristina Moreira Marcos}

Programa de Pós-Graduação Stricto Sensu em Psicologia PUC Minas

Avenida I taú, 525, Dom Cabral, CEP 30535-012, Belo Horizonte - MG, Brasil

Endereço eletrônico: cristinammarcos@gmail.com

Recebido em: 14/07/2014

Reformulado em: 26/08/2014

Aceito em: 17/09/2014

\section{Notas}

* Docente do Programa de Pós-Graduação em Psicologia da Pontifícia Universidade Católica de Minas Gerais. Belo Horizonte/Brasil. Doutora em Psicanálise pela Universidade de Paris 7.

1 O Núcleo de Investigação em Anorexia e Bulimia do Hospital das Clínicas da Universidade Federal de Minas Gerais foi fundado em 2004 e agrega médicos, psicólogos e nutricionistas orientados pelo referencial teórico e clínico da psicanálise lacaniana. O caso Nina foi publicado em CUNHA, C. F.; LIMA, N. L. (2002) e foi discutido nas reuniões da pesquisa "As manifestações do ato e sua singularidade em suas relações com o feminino", financiada pela Fundação de Amparo à 
Pesquisa/FAPEMIG (APQ 01074-10) e pelo Programa de Incentivo à pesquisa do Pró-Reitoria de Pesquisa e Pós-Graduação da PUC-Minas (FIP 5865). O artigo faz parte ainda das discussões desenvolvidas na pesquisa "Anorexia e Sexuação Feminina", financiada pela FAPEMIG (APQ - 01012-13) e pela Pró-Reitoria de Pesquisa e Pós-Graduação da PUC-Minas (FIP 8497), que dá continuidade à pesquisa anterior. 